\title{
18. ve 19. Yüzyıl Avrupa Resim Sanatında Akdeniz
}

\section{The Mediterranean in the $18^{\text {th }}$ and $19^{\text {th }}$ century European Art of Painting}

\begin{abstract}
Sibel ALMELEK İŞMAN*
Öz: Akdeniz, Avrupa, Asya ve Afrika'nın ortasında yer alan, her birinin kültüründen etkilenen, zengin geçmişi ve doğası ile dikkat çeken bir bölgedir. Çeşitli üsluplarda eser veren Avrupalı ressamların, yüzyıllar boyunca Akdeniz'i tuvallerine taşıdıkları görülmektedir. Rönesans döneminden başlayarak Avrupa sanatı incelendiğinde, Akdeniz'in insanları, manzaraları ve doğal ürünlerinin betimlendiği görülebilir. Bu çalışmada, 18. ve 19. yüzyıl Avrupa resim sanatının Akdeniz yorumları değerlendirilecektir. Rokoko, Yeni Klasikçilik, Romantizm, Akademik Resim ve İzlenimcilik akımlarında, Akdeniz'i anlatan çeşitli resim örnekleri araştırılmıştır. Hellen ve Roma mitolojilerindeki öykülerde, Akdeniz'in kıyıları, adaları, dağları ve ırmaklarından söz edilmektedir. Mitolojik öyküleri tuvallerine aktaran sanatçılar, mekân olarak Akdeniz'i değerlendirmişlerdir. Akdeniz'in arkeolojik zenginliği, klasik Hellen ve Roma uygarlıklarıyla kurduğu köprü sanatçıların dikkatini çekmiştir. Akdeniz’in batılı olduğu kadar doğulu olan yüzü de resimlere konu olmuş; Oryantalist eserler, Akdeniz'in güneyindeki ve doğusundaki kültürleri yansıtmıştır. Gerek Akdeniz'de doğup büyümüş, gerekse de Kuzey Avrupa ülkelerinden gelmiş sanatçılar, Akdeniz'in güneşini, 1şığını ve sunduğu güzellikleri hayranlıkla görselliğe kavuşturmuşlardır.
\end{abstract}

Anahtar sözcükler: Avrupa resmi, Akdeniz, 18. yüzyıl, 19. yüzyıl

Abstract: The Mediterranean Sea, located at the junction of Europe, Asia and Africa, and affected by each continent's culture, is an attractive region with its rich past and nature. European painters who worked in various styles, depicted the Mediterranean region throughout the centuries. When European art is observed from the Renaissance onwards, it can be seen that the people, landscape and the natural products of the Mediterranean have been depicted. This essay will focus on the Mediterranean images from European painting dating from the $18^{\text {th }}$ and $19^{\text {th }}$ centuries. Pictures that represent the Mediterranean in the periods of the Rococo, Neoclassical, Romantic in, Academic Painting and in Impressionism will be explored. Shores, islands, mountains and rivers of the Mediterranean region are mentioned in Greek and Roman mythology. Artists who depict mythological stories on their canvases, used the Mediterranean as a background. Painters were attracted to the archeological richness of the landscape around the Mediterranean Sea and the bridge that she forms between the present day and the ancient days classical of Greek and Roman civilization. The Western as well as the Eastern face of the region was the subject of these paintings. Orientalist pictures represented the cultures of the Eastern and Southern Mediterranean. Both the artists who were born and raised in the Mediterranean and those who came from Northern European countries depicted with enthusiasm the sun, light and beauties of the region.

Keywords: European painting, The Mediterranean, $18^{\text {th }}$ century, $19^{\text {th }}$ century

Ilıman iklimi, dantel gibi koyları ve çeşitli adalarıyla zengin bir bölge olan Akdeniz, uygarlığın gelişiminde önemli bir rol oynamış, müzik, edebiyat, sanat ve bilimin merkezi olmuştur. Dünyanın en büyük iç denizi olan Akdeniz, dünya dillerindeki yaygın adıyla Mediterranean Sea,

\footnotetext{
* Dr., Dokuz Eylül Üniversitesi, Buca Eğitim Fak., Resim-İş Öğretmenliği Bölümü., İzmir, almelek14@hotmail.com
} 
yani kıtalar ortasındaki deniz, Asya, Afrika ve Avrupa'nın arasında yer almaktadır.

Avrupa resim sanatında, Akdeniz'in, Akdeniz'de yaşayan insanların ve bu denizi paylaşan farklı kültürlerin izleri arandığında, renkli bir dünya ile karşılaşılır. Üç kıtanın, Avrupa, Asya ve

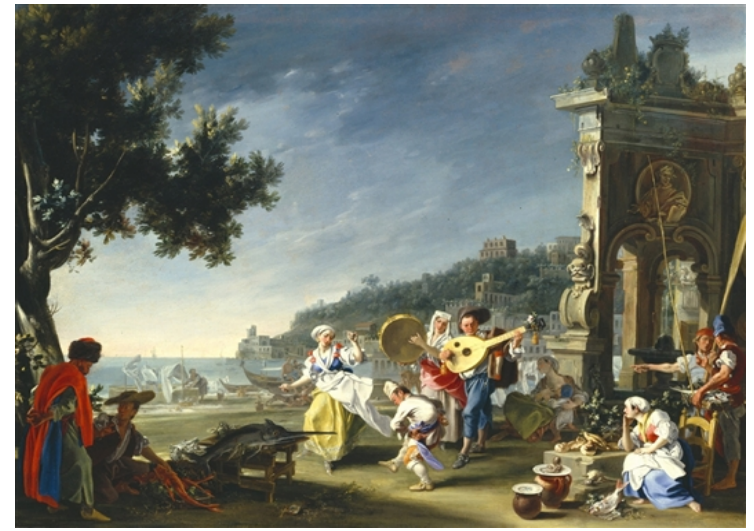

Fig. 1. Filippo Falciatore, Mergellina'da Tarantella, yak. 1750, tuval üzerine yağlıboya, 76,2 x 102, cm, Detroit Institute of Arts, Michigan.

Afrika'nın yerel özellikleri, bir denizin çevresinde, etkileşim içinde var olmaktadır. Akdeniz kadınlarının güzelliği, tuvallerde yeniden hayat bulur. Bir resim İtalyanların dansını yansitırken, diğeri Cezayir'deki festivali canlandırır. Bereketli Akdeniz toprăğ, zengin ürünleriyle betimlenir.

18. ve 19. yüzy1lların Avrupa sanat1, birbirini izleyen ve hatta birbiriyle ayn anda var olan farklı üsluplarıyla, dinamik bir görünüm kazanmıştır. 18. yüzyılın ortasina kadar etkili olan Rokoko'ya tepki olarak doğan Yeni Klasikçilik, Romantizm akımı ile çağdaştır. Aşağı yukarı 19. yüzy1lın ortasına kadar süren Yeni Klasikçilik ve Romantizmi, 1870 ve 1880'li yıllarda ortaya çıkan Akademik Sanat izlemiştir. İzlenimcilik akımı ise, 20. yüzyıla yaklaşırken sanat dünyasına yeni bir ışık getirmiştir. Akdeniz'i, doğası, insanı ve öyküleriyle betimleyen 18.-19. yüzyıl Avrupa resimlerine, çeşitli örnekler verilebilir.

Rokoko döneminin İtalyan ressamlarından Filippo Falciatore (1728-1768), Mergellina'da Tarantella (yak. 1750) adlı resminde (Fig. 1) açık havada yapılan bir dansı betimlemiştir. Mergellina, Napoli'ye yakın bir kenttir. Resmin arka planındaki tepe üzerinde yer alan birkaç yapının, bu İtalyan kentine ait olduğu düşünülebilir. İki tane müzisyene eşlik eden coşkulu

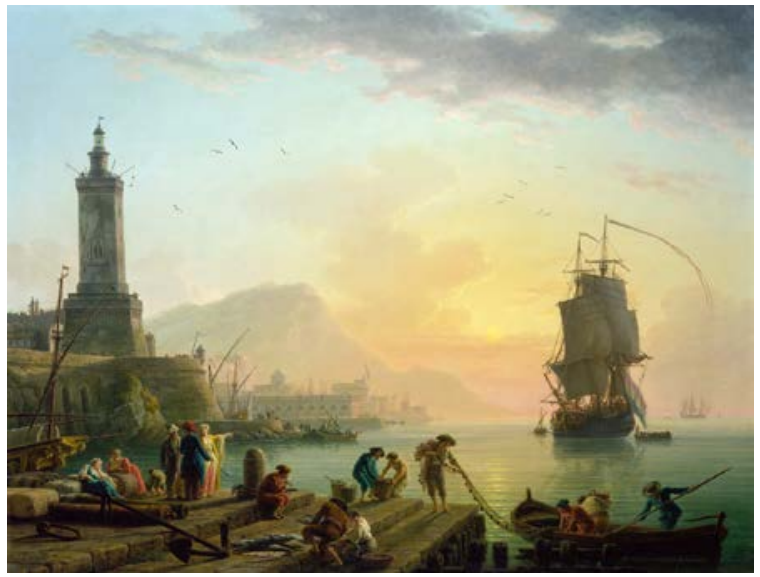

Fig. 2. Claude-Joseph Vernet, Bir Akdeniz Limanı'nda Sükûnet, 1770, tuval üzerine yağlıboya, J. Paul Getty Museum, Los Angeles. kadın ve erkek, Tarantella dans1 yapmaktadırlar. Sol tarafta bir balık satıcısı ve belki de onunla pazarlık yapan müşterisi; sağda ise bebeğini emziren bir anne, denizden dönmüş balıkçılar ve sandalyede oturup hülyalı bir şekilde dans edenleri izleyen bir kadın dikkat çekmektedir. Falciatore, akşamüstü saatlerinde, denizin kenarında vakit geçiren Akdeniz insanının huzurunu yansıtmıştır.

Akdeniz, yüzyıllar boyunca, manzara ressamlarına ilham vermiş, güneşin sarı coşkusu, gökyüzünün değişen renkleri, denizin mavisi ve doğanın yeşili tuvallere aktarılmıştir.

18. yüzy1l Fransız manzara ressamlarindan Claude-Joseph Vernet (1714-1789),

1734-1753 yılları arasında Roma'da çalışmış, Barok sanatçı Claude Lorrain'in (1600-1682) resimlerindeki 1şıktan etkilenmiştir. Yaşadığı dönemde çok moda olan idealize edilmiş ve duygularla yüklenmiş manzara sanatının seçkin örneklerini veren sanatçı, özellikle deniz kıyıları ve liman betimlemeleriyle ünlenmiştir. Vernet, 1753 yılında Paris'e döndügünde, Fransa Kralı 15. Louis’ten Fransa'nın limanlarını gösteren bir resim serisi için sipariş almıştır (Chilvers, 2009, 
655). Vernet, kırmızı, turuncu ve sarı renklerin yumuşak tonlarını yansıtan 1770 tarihli Bir Akdeniz Limanında Sükûnet adlı eserinde (Fig. 2), sakin geçen bir günden sonra gelen günbatımı sahnesini betimlemiştir. Balıkçılar, kayıklarını temizleyip, ağlarını toplamaktadırlar. Limandaki insanlar sohbet etmekte; oryantal giysili bir grup, limana yanaşmış olan bir gemi hakkında konuşmaktadırlar. Sol tarafta bir deniz feneri, daha uzakta ise adını bilmediğimiz bir kentin silueti dikkat çekmektedir. Deniz sakinken, kent ve insanlarına tatlı bir huzur duygusunun hâkim olduğu görülmektedir. Vernet, bu resimden üç sene önce tamamladığı Bir Akdeniz Limanı'nda Fırtına (1767) adlı eserinde ise, denizin bambaşka bir halini canlandırmış, kızgın dalgaların üzerinde uzanan karanlık bulutlar yansıtmıştır. Vernet, her iki tuvalinde de, insanların deniz ile kurduğu ilişkiyi yansıtmaktadır. Akdeniz, kimi zaman yardımseverliği, kimi zaman ise öfkesi ile kıyılarında yaşayan insanların yaşamlarına dokunmaktadır.

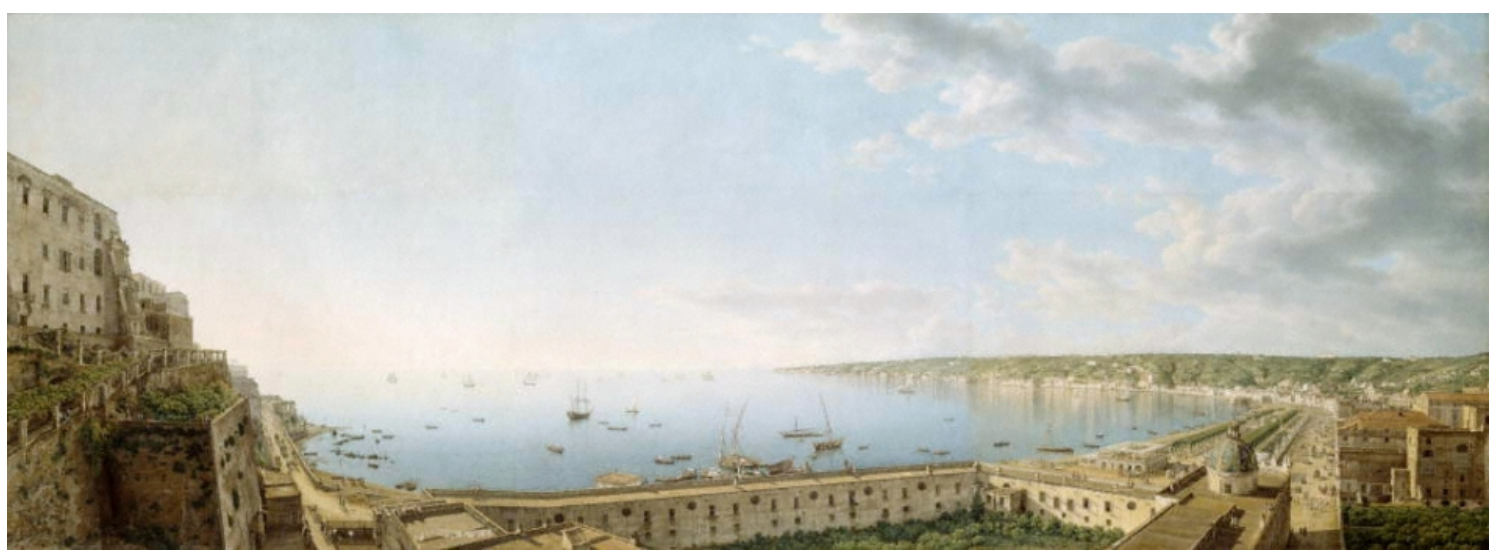

Fig. 3. Giovanni Battista Lusieri, Napoli Körfezi Manzarası: Pizzofalcone'den Capo di Posilippo'ya Güneybatı Baklşı, 1791, altı tane kâğıt üzerine suluboya, guaş ve mürekkep, J. Paul Getty Museum, Los Angeles.

Kent ya da kırsal kesim manzaralarını gerçekçi bir üslupla tuvallere aktaran Vedutismo (Vedutizm) akımının değerli isimlerinden biri olan İtalyan sanatçı Giovanni Battista Lusieri (17551821), 1791 tarihli Napoli Körfezi Manzarası: Pizzofalcone'den Capo di Posilippo’ya Güneybatı Bakışı adlı eserinde (Fig. 3), Napoli Körfezi'ni hem doğasına hem de mimarî yapısına sadık kalarak betimlemiştir. Lusieri, en cesur çalışmalarından biri olan bu resmi, altı büyük kâğıda suluboya, guaş ve mürekkep kullanarak yaratmıştır. 1764-1799 yılları arasında, Napoli'de İngiliz elçisi olarak görev yapan Sir William Hamilton'un yaşadığı Palazzo Sessa'dan (Sessa Saray1) izlenebilen bu manzara, elçinin gri renkli İngiltere'ye döndügü zaman güneşli ve işıklı Napoli manzarasının tadını çıkarabilmesi ve hatıralarını canlandırabilmesi için sipariş verilmiştir. Aradan geçen iki asrı aşkın zamanın getirdiği kentsel gelişime rağmen, resmin yansıttığ körfezin topografyası bugün bile tanınabilir durumdadır (Tarabra, 2008, 62-63).

Grand Tour (Büyük Tur) olarak bilinen, 18. yüzyılda, Avrupalı aristokrasi ve burjuvazi mensubu kişilerin, büyük Avrupa kentlerine, özellikle de İtalya'ya yaptıkları geziler, canlı bir sanat pazarı yaratılmasına da katkıda bulunmuştur. Rahip ve yolculuk yazarı Richard Lassels (1603-1668), 17. yüzyılın sonuna doğru kaleme aldığı "Bir İtalya Yolculuğu" adlı kitabında, sadece İtalya ve Fransa'yı ziyaret edenlerin, Caesar ve Livius’u gerçekten anlayabileceklerini ifade etmiştir. Kısa zamanda yaygınlaşan Büyük Tur, kültürel bir eğitim ve hümanist çalışmaları tamamlayan bir deneyim olarak algılanmıştır. Büyük ses getiren Pompeii ve Herculaneum kazılarından sonra, Napoli, Paestum ve Sicilya gibi yerler de tura katılmıştır. Kuzey Avrupalı gezginler, antik sanat hazineleri ve muhteşem manzaraları nedeniyle İtalya'nın Akdeniz sahillerinde, bazen aylarca hatta yıllarca kalmışlardır. Grand Tourist (Büyük Turist) olarak anılan bu 
gezginler, evlerine sanat objesi, giysi, değerli taş ve kurutulmuş çiçek gibi çeşitli hediyelerle dönmüşlerdir. En sevilen hatıralar ise, ünlü mekânların ve kişilerin resimleri olmuştur (Tarabra, 53).

Yeni Klasikçi ustalardan Johann Heinrich Wilhelm Tischbein (1751-1829), 1787 tarihli Goethe Roma'nın Kırlarında adlı resminde (Fig. 4), Roma'da uzun zaman dilimlerinde aynı evi paylaştıkları, Roma ve Napoli civarındaki arkeolojik alanları birlikte ziyaret ettikleri yakın arkadaşı yazar Johann Wolfgang von Goethe'yi (17491832) antik döneme ait taşların üzerinde otururken betimlemiştir. Goethe, geçmişe ait anıtlarla dolu geniş bir kırsal alanı, dalgin gözlerle seyretmektedir. Taşlar ve sütun başlıkları gibi çeşitli arkeolojik buluntuların yanında, üzerinde Iphigenia, Orestes ve Philades'in figürlerinin bulunduğu bir rölyef dikkat çekmektedir. Tischbein, resmine

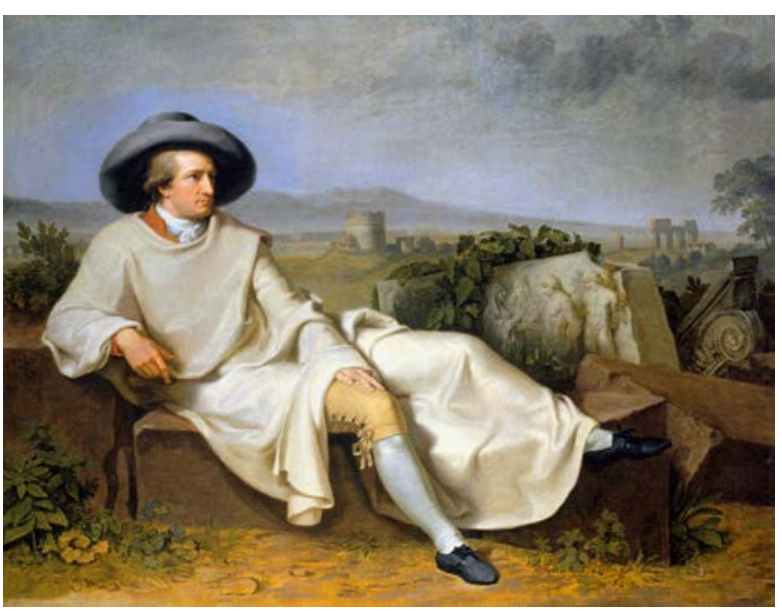

Fig. 4. Johann Heinrich Wilhelm Tischbein, Goethe Roma'nın Kırlarında, 1787, Städelsches Kunstinstitut, Frankfurt. incelikle kattığı bu detayla, Goethe'nin o dönemde üzerinde çalıştığı "Iphigenia Tauris'te" adlı oyununa gönderme yapmaktadır. Avrupa'da eğitimli sınıfların bir çeşit ritüeli haline gelen ve yaşamın akışını değiştiren bir deneyim olarak algılanan Büyük Tur'u yapan aydınlardan biri olan Goethe, bu resimde otuz yedi yaşında öğrenmeye ve keşfetmeye aç bir yazar olarak karşımıza çıkmaktadır (Tarabra, 56).

Jacob Philipp Hackert (1737-1807), 18. yüzyılı etkileyen arkeoloji heyecanını tuvallerine taşıyan diğer bir ressam olarak dikkat çekmektedir. Sanatçı, 1799 tarihli Pompeii Kazılarl adlı eserinde (Fig. 5), geniş bir Napoli Körfezi manzarası içine, Pompeii kentinin kalıntılarını yerleştirmiştir. Hackert, 1792 ve 1794 yılları arasında, Pompeii kazılarını birkaç kez betimlemiştir. Amfi tiyatrosu, evleri ve sokaklari ile detaylı bir şekilde gösterilen Pompeii kentinin yakınındaki tepede birkaç kişi ve hayvan, sakin havanın tadını çıkarmaktadır. Kırsal yaşamın bu huzurlu üyeleri, antik Pompeii

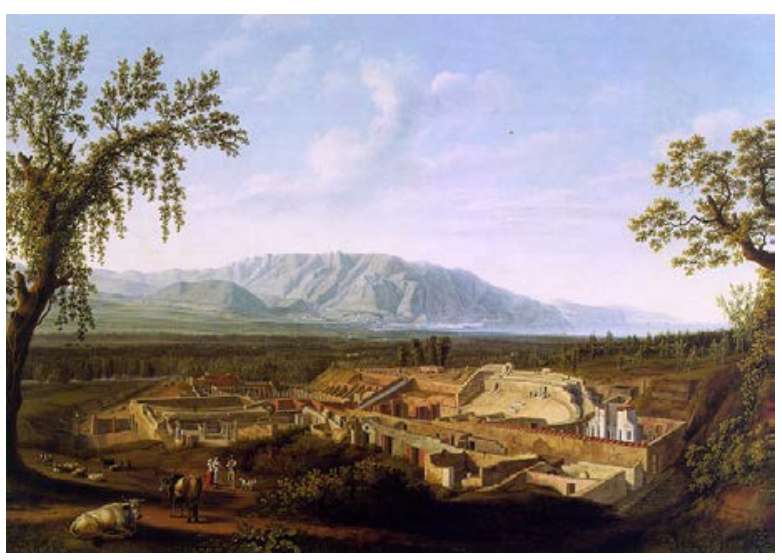

Fig. 5. Jacob Philipp Hackert, Pompeii Kazılarl, 1799, tuval üzerine yağlıboya, Attingham Park, Shropshire. zamanından bu yana bazı şeylerin değişmediğini hatırlatmak ister gibidir (Tarabra, 78). Tischbein gibi, Goethe ile yakın arkadaş olan Hackert, 1790 tarihli Goethe Colosseum'u Hayranlıkla İzlerken adlı resminde, hem Goethe ile kurduğu dostluğu hem de onunla paylaştığı antik Roma uygarlığı ve Colosseum hayranlığını ölümsüzleştirmiştir. 


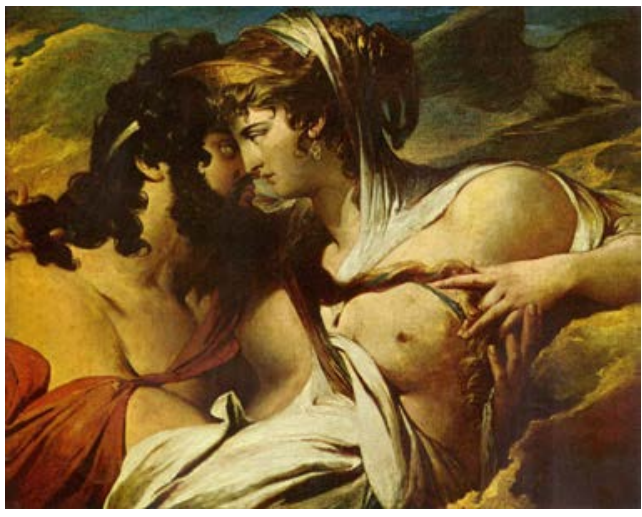

Fig. 6. James Barry, Jüpiter ve Juno İda Dă̆ı'nda, 1790-99, tuval üzerine yağlıboya, 130,2 cm x 155,4 cm, Sheffield City Museum, Sheffield.

Hellen ve Roma mitolojilerinde, Akdeniz dünyasına ait pek çok deniz, ırmak, ada, yarımada, dağ, kent ve limanın adı geçmektedir. Tanrı, tanrıça ve kahramanların yaşam öykülerinde, coğrafî detaylar da dikkat çekmektedir. Tanrıların babası sayılan Zeus'un çocukluğu, Girit Adası'ndaki İda Dağı'nda geçmiştir. Sanata ilham veren Musa'lar, Helikon Dağı'nda otururlardı. Musa'lara emanet edilen uçan kanatlı at Pegasos'un attığı bir çifteyle, bu dağda Hippokrene adlı bir pınar meydana gelmiştir (Necatigil, 1969, 58-60). İrlandalı Yeni Klasikçi ressam James Barry (1741-1806), Jüpiter ve Juno İda Dă̆ı 'nda (1790-1799) adlı resminde (Fig. 6), tanr1ların lideri Jüpiter ve eşi evlilik tanrıçası Juno’yu, İda Dağı'nın tepesinde, bulutların arasında aşklarını yaşarken betimlemiştir.

Romantizm döneminin değerli ismi Eugène Delacroix (1798-1863), Akdeniz’i alegorik bir anlatımla sunmuştur. 1837 yılı süresince, Paris’teki Palais Bourbon'daki (Bourbon Sarayı) Salon du Roi'nın (Kral Salonu) tavan süslemeleri üzerinde çalışan sanatçının, klasik giysiler

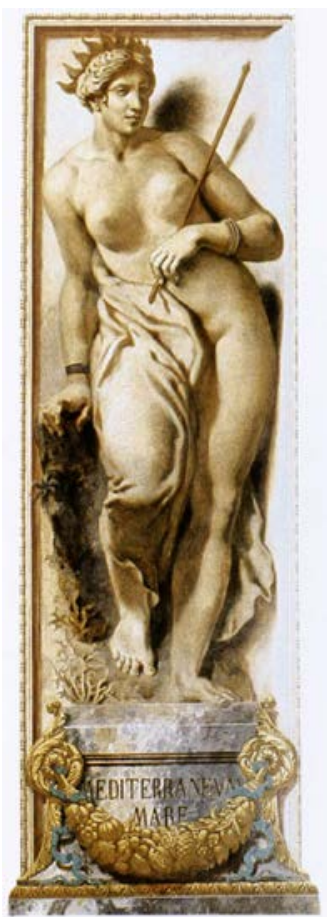

Fig. 7. Eugène Delacroix, Akdeniz, 1837, siva üzerine yağlıboya ve balmumu, 122 x 300 cm. Salon du Roi, Palais Bourbon, Paris. içinde betimlediği dört büyük alegorik figür, Adalet, Tarım, Endüstri ve Savaş isimlerini taşımaktadır. Sanatçı, sütunların üzerinde yer alan resimlerde ise, Fransa'nın nehirlerini ve onların içine aktıkları deniz ve okyanusları kişileştirmiştir. Akdeniz (Fig. 7), bir kaidenin üzerinde ayakta duran yarı çıplak kadın heykelinin resimsel yansıması olarak dikkat çekmektedir (Néret, 2004, 72). Klasik kadın güzelliğini yansıtan figürün başında, Akdeniz güneşinin 1şınlarını andıran bir taç vardır.

Akdenizli kadın imgesini değerlendiren sanatçılar arasında, Fransız akademik resim anlayışında eser veren Jules Joseph Lefebvre'nin (18361911) adı anılabilir. 1861 yılında, Prix de Rome'u (Roma Ödülü) kazanan sanatçı, bir süre Roma'da bulunmuştur (Norman, 1977, 130). Lefebvre, Akdeniz Güzeli adlı resminde (Fig. 8), elinde başak taneleri tutan, kırmızı siyah giysili bir köylü kadını betimlemiştir. Düşüncelere dalmış ve gözlerini uzakta bir yere çevirmiş olan kadının saçlarını, desenli eşarbı örtmektedir. Akdeniz güzelinin beyaz ten rengi, üzerindeki koyu giysiyle tezat yaratmaktadır. Resmin sol tarafında, kadının köyüne uzak bir noktada, Akdeniz olduğunu düşünebileceğimiz bir mavilik uzanmaktadır. Hem Fransız hem de İtalyan kültürlerini yakından tanıyan Lefebvre'nin, bu güzel kadını yaratırken, her ikisinden de ilham aldığ düşünülebilir.

Akdeniz'in kıyısındaki ülkelerde yaşayan insanlar, dinsel inanç ve yaşam biçimleri açısından farklı olsalar da, benzer bir damak tadına sahiptirler. Akdeniz mutfağı, çeşitliliği ve yenilik-

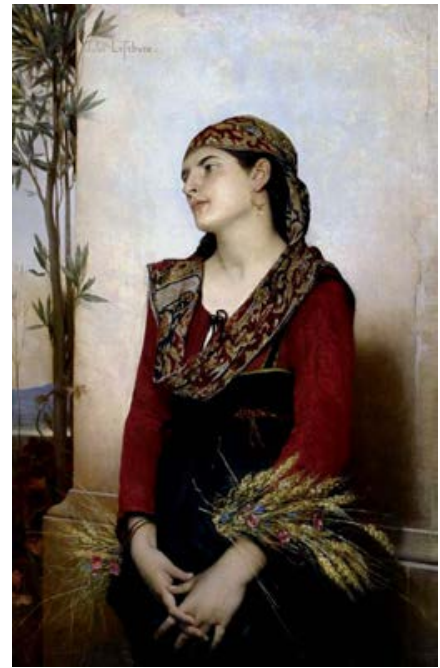

Fig. 8. Jules Joseph Lefebvre, Akdeniz Güzeli, pano üzerine yağlıboya, 34 x $51,5 \mathrm{~cm}$. Özel Koleksiyon. 
lere açık oluşu ile dikkat çekmektedir. Akdeniz'de yetişen balıkların, meyve ve sebzelerin zenginliği, yemeklerinin renk ve kokusu, yabancıların da hayranlığını kazanmaktadır. İngiliz yazar D. H. Lawrence (1885-1930), İtalya'nın Sardinya Adası'nı ziyaret ettiği zaman, günlügüne yemeğin bolluğu ve pazarlardaki ürünlerin güzelliği hakkında notlar düşmüştür (Helstosky, 2009, 1-2). Tazelik, çeşitlilik ve sıhhat sunan Akdeniz ürünleri, resim sanatında da iştah açan imgeler yaratmaktadır. Denizde balıklar, karada portakal, limon, üzüm ve zeytinler, Akdeniz'in değerli simgeleri haline gelmişlerdir.

19. yüzyıl ressamlarından Karl Blechen (1797-1840), Almanya'daki doğalcı manzaraanlayışının kurucuları arasında sayılmaktadır. Eserlerindeki duyarlı ifade onu Caspar David Friedrich (1774-1840) gibi Romantik resim geleneğinin ustalarına, parlak ve özgür renk kullanımı ise Adolph von Menzel (1815-1905) gibi İzlenimcilik akımının gelişiminde rol alan sanatçılara yakınlaştırmaktadır. Berlin Akademisi'nde çalışmaya başlamadan önce, 1828-

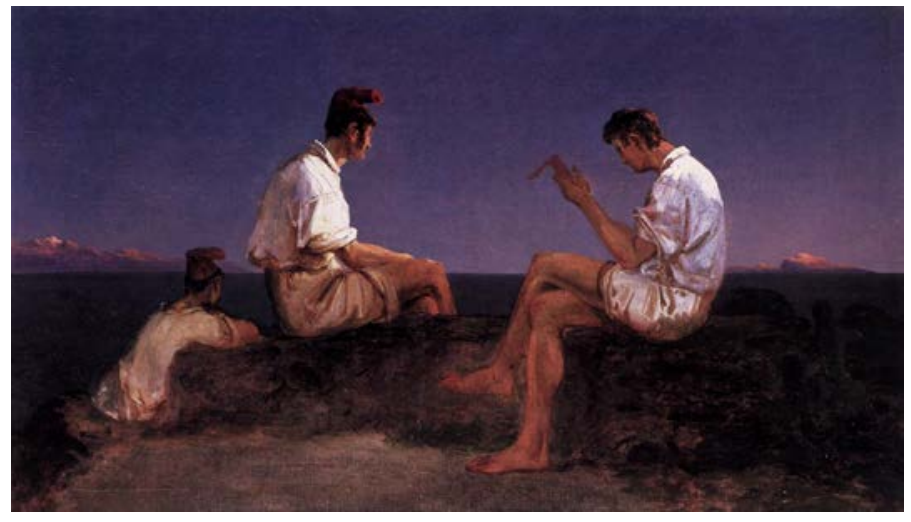

Fig. 9. Karl Blechen, Napoli Körfezi'nde Balıkçılar, 1830, tuval üzerine yağlıboya, 20 x $34 \mathrm{~cm}$, Nationalgalerie, Berlin. 29 yıllarını İtalya' da geçiren Blechen, Akdeniz'den manzaralar ve günlük yaşam sahnelerini tuvallerine taşımıştır (Norman, 41). Sanatçının 1830 tarihli Napoli Körfezi'nde Balıkçılar adlı resmi (Fig. 9), gün henüz yeni doğarken, sahilde balık bereketini bekleyen üç erkek figürünü canlandırmaktadır. Gökyüzünün ve denizin koyu mavisi, balıkçıların beyaz gömlek ve şortlarıyla tezat oluşturmaktadır. Doğanın uyanışını izleyen ve balık avının dinginliğini yaşayan üç erkek, belki biraz da uyku mahmurluğuyla, hiç konuşmamakta, birbirleriyle sessizliği paylaşmaktadırlar.

İzlenimci kadın ressam Berthe Morisot (1841-1895), 1882 tarihli Nice'de Portakal Ağaçlı Villa adlı resminde (Fig. 10), güneşin aydınlattığı mavi bir gökyüzünün altında, güzel bir villa betimlemiştir. Villanın önünde uzanan bahçede serpilmiş portakal ağaçları resmin ön planında yer almakta, sanki izleyiciyi aralarında dolaşmaya davet etmektedir. Nice, Morisot'nun sevdiği bir beldedir. Çeşitli seferler geldiği Nice'in plajlarını da tuvallerine aktaran Morisot, 1888 yılının Kasım ayında, eşi ve kızı ile birlikte, kentin yakınında yer alan ve sanatçının "kusursuz sayfiye" diye tanımladığı Cimiez'de, büyük bir bahçesi olan Villa Ratti'ye yerleşmiştir. Morisot'nun eşi Eugene Manet'nin, Lewis Brown adlı arkadaşına yazdığı 21 Kasım tarihli bir mektubunda şu sözler dikkat çekmektedir: "Eşim çalışıyor. Işı̆̆g göz alıcı bir şekilde yansitan portakal ve zeytin ağaçlarına âşı oldu”. Karı koca en yakın arkadaşlarını evlerine davet etmişler, turunçgilleri ve kurutulmuş yaprakları kuzeye hediye olarak göndermişlerdir. Ailece tepeleri gezmişler, Mo-

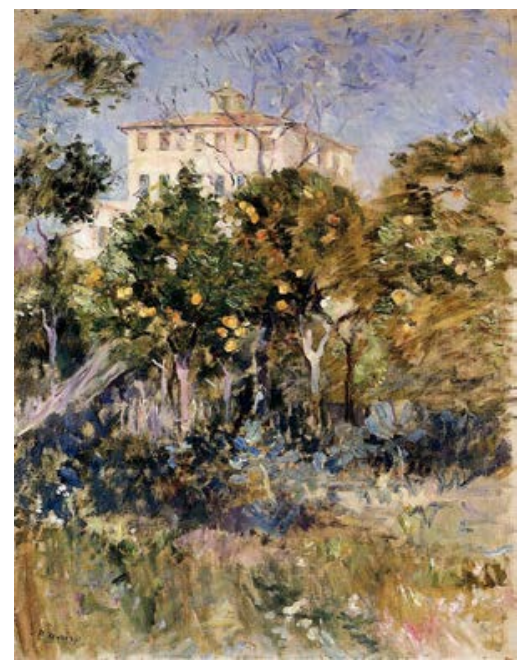

Fig. 10. Berthe Morisot, Nice'de Portakal Ağaçlı Villa, 1882, tuval üzerine yağlıboya, Özel Koleksiyon. risot dışarıda hem piknik hem de resim yapmanın tadına varmıştır. Morisot, arkadaşı Emma'ya hitap ettiği mektubunda şöyle yazmıştır: "Portakalları sert değil de, Floransa'da gördügü̈m 
Botticelli resmindeki gibi betimlemeye çalışlyorum. Bu gerçekleşmeyecek bir rüya... Buranın tüm genç manzara ressamları için neden büyük bir atölye gibi algılanmadığını anlayamıyorum. Güzelliğinin yanı sıra, sakin iklimi sayesinde de en ince araştırmalara olanak sağllyor" (Higonnet, 1995, 199).

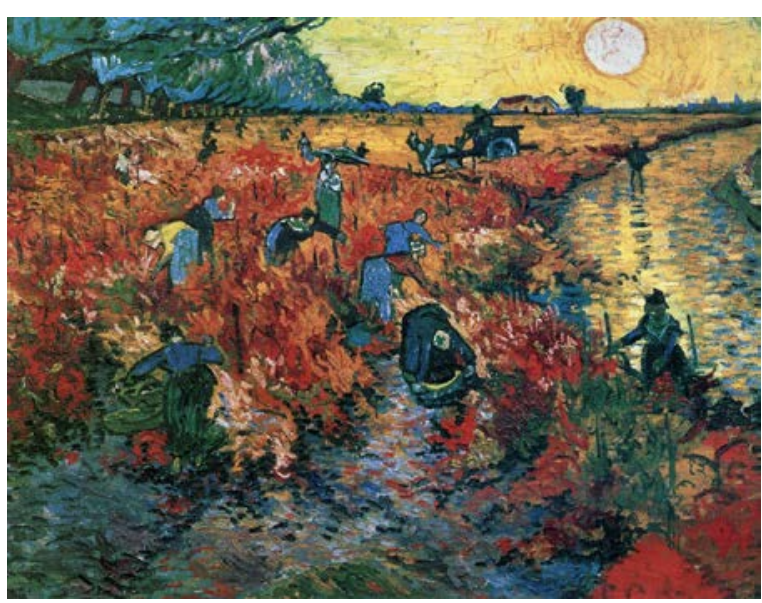

Fig. 11. Vincent van Gogh, Arles 'te Kırmızı Bağ, 1888, tuval üzerine yağlıboya, 75 x $93 \mathrm{~cm}$, Pushkin Museum, Moskova.

Art İzlenimci usta Vincent van Gogh (18531890), 1888 y1lının Şubat ayından 1889 y1lının Mayıs ayına kadar, Fransa'nın bir güney kasabası olan Arles'te yaşamıştır. Sanatçı bu onbeş aylık süre boyunca, iki yüz resim, yüzü aşkın suluboya çalışması ve çizim yapmış; kardeşi Theo'ya iki yüz tane mektup yazmıştır. Van Gogh'tan önce hiçbir sanatçı, Arles'e yerleşip, orada bir sanat geleneği oluşturmamıştır. Sanatçı, Arles'in keyfini yaşamak ve kendisine güneyde bir atölye yaratmak istemiş olmalıdır (Walter, 1984, 11-12). Van Gogh, bu dönemde yaptığı Arles'te Kırmızı Băg (1888) adlı resminde (Fig. 11), Arles’teki üzüm hasadı telaşını ve doğanın cömertliğini yansıtmıştır. Van Gogh'un coşkulu ve yoğun firça darbeleri, güneşin gücünü gösteren sarıda ve üzümlerin bereketini gösteren kırmızıda hissedilmektedir.

Sanatçı, 1889 yılının Mayıs ayında, St. Remy'deki akıl hastanesine yattığı ilk günlerde hastanenin içini ve odasından görebildiği manzarayı betimlemiş; kendisini daha güçlü hissettiği Haziran'ın ikinci haftasından itibaren, dışarıdaki yaşamı resmetmeye başlamıştır. Van Gogh, kırlarda ve ağaçların arasında dolaşmanın, yaşama sevincini tekrar kazanmasını sağladığını ifade etmiştir. Zeytin ağaçlarından görür görmez etkilenen sanatçı, onları pek çok kez tuvaline yansitmıştır. Sarı Güneş ve Gökyüzü ile Zeytin Ağaçları (1889) adlı resmi (Fig. 12), bu döneme ait çalışmalardan biridir. Kardeşi Theo’ya yazdığı mektupta, Gauguin'in üzerinde çalıştığını söylediği İsa Zeytin Bahçesinde (1889) adlı dinsel resmiyle yakınlık kurduğunu ifade etmiştir. Van Gogh, zeytini kutsal bir sembol olarak değerlendirmiş, onu olduğu gibi yansıtmak yerine derin

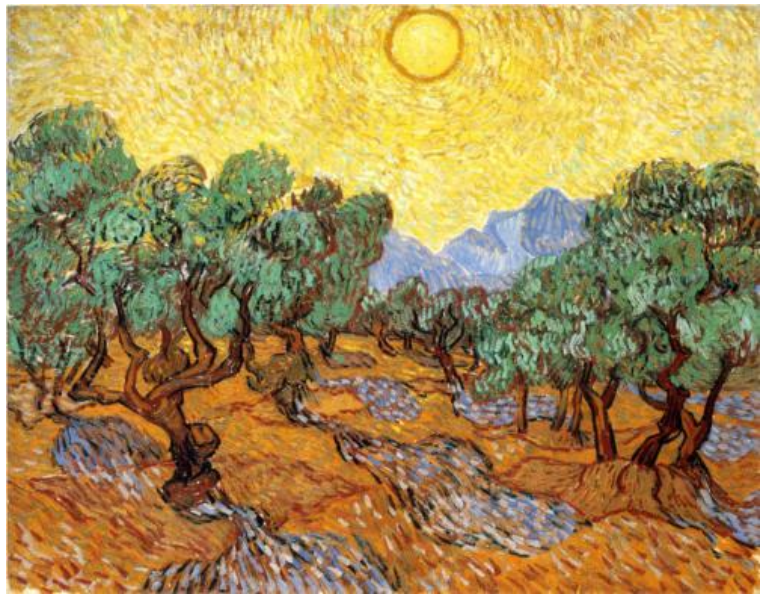

Fig. 12. Vincent van Gogh, Sarı Güneş ve Gökyüzü ile Zeytin A ğaçları, 1889, tuval üzerine yağlıboya, 73,7 x 92,7 cm, Minneapolis Institute of Arts, Minnesota. ruhsal anlamlar yükleyerek manzaranın içine yerleştirmiştir (Maurer, 1999, 90). Kudretiyle bütün doğayı uyandıran sarı güneş, uzaktaki dağların gökyüzüne değen zirveleri, yeşil gür yaprakları ve güçlü gövdeleri ile topraktan güç alan zeytin ağaçları, sanatçının cesur üslubu ile etkili bir bütün yaratmışlardır.

Akdeniz'i anlatan resimler düşünüldüğü zaman, 19. yüzyıl Avrupa sanatında önemli izler birakan Oryantalizm tutkusunu da değerlendirmek gerekir. Doğudaki ülkelerin dil, din ve yaşam şekillerine merakla yaklaşan batılı sanatçılar, Mısır, Cezayir, Fas ve Tunus gibi güney Akdeniz ülkelerinin doğasını, insanlarını ve kentlerini pek çok kez tuvallerinde yansıtmışlardır. 
İzlenimcilik akımının ustalarından Pierre Auguste Renoir (1841-1919), Oryantalizm ile İzlenimciliği buluşturmuş, doğu gezilerini ışıklı bir dille tuvaline aktarmıştır. Renoir'ın, 1881 yılında, Cezayir'den arkadaşı Paul Durand-Ruel'e yazdığı mektupta, şu sözler dikkat çekmektedir: “Burada bir ay daha kalacă̆ım. Cezayir'den, bu olağanüstü ülkeden elim boş dönmek istemiyorum” (Antmen, 2008, 28).

Arap Festivali (1881) (Fig. 13), Renoir'ın 1881 ve 1882 bahar aylarında Cezayir'e yaptığı yolculuklardan gelen bir düzine resim içinde en önemlisi olarak değerlendirilir. Renoir'ın betimlediği kutlama tam olarak saptanamamıştır. Bu bir dinsel kutlama olabilir ya da daha büyük bir olasılıkla, Kuzey Afrikalı gezgin müzisyenlerin gösterileri olarak düşünülebilir. Resmin merkezinde, büyük bir kalabalığın ortasında, tef ve flüt çalan beş müzisyen halka oluşturmuşlardır.

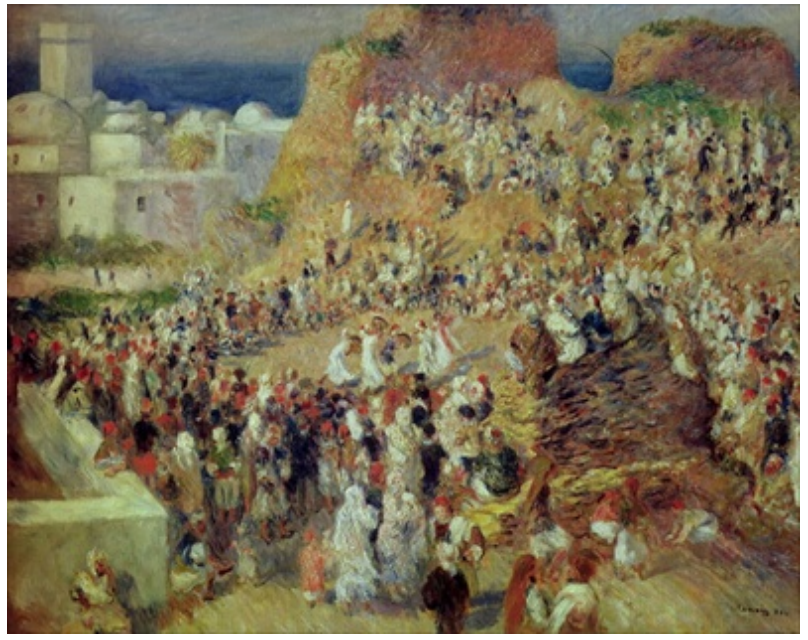

Fig. 13. Pierre Auguste Renoir, Arap Festivali, 1881, tuval üzerine yağlıboya, 73,5 x 92 cm, Musée D’Orsay, Paris. Kadın, erkek ve çocuklar, hayaletler gibi, tepenin ham toprağında doğal olarak oluşmuş bir amfi tiyatronun içinde dağılmışlardır. Denizin sisli mavisinin yanında, kule ve kubbeleriyle “Beyaz Cezayir”, bu oldukça renkli kompozisyona fon oluşturmaktadir (Benjamin, 1997, 133).

Arap Festivali, Renoir'ın Cezayir resimleri arasında ayrıcalıklı bir yere sahiptir çünkü manzara ve figür çalışmaları arasında, yerel bir geleneği betimleyen tek eserdir. Renoir, Cezayir anılarında, gün 1şığının alçakgönüllü dilencileri bile nasıl efsanevî kişiliklere dönüştürdügünü dile getirmiştir. Sanatçı, Cezayir'de beyazı keşfettiğini vurgulamıştır (Raeburn, 1985, 226). Bu resimde de caminin beyazı ve kalabalığın içindeki bazı insanların giysilerindeki beyaz, güneşin altında parlamaktadır.

Fransız tarihçi Fernand Braudel'in (1902-1985) "Nedir bu Akdeniz? Binbir şeyin hepsi birden. Bir manzara değil, sayısız manzaralar. Bir deniz değil, birbirini izleyen birçok deniz. Bir uygarlık değil, birbiri üzerine yı̆̆llmış birçok uygarlık" (Braudel, 2008, 9-10) sözleriyle engin doğasını ve tarihini övdügü Akdeniz, Avrupa resim sanatına da zenginlik katmıştır. Akdeniz'de doğmuş olan, Akdeniz'e gönül verip kıyılarını ziyaret eden ya da bu güneşli kentlere yerleşen Avrupalı sanatçılar, Akdeniz'i tüm zenginliğiyle betimlemiş; doğası, insanları, kentleri ve mitolojik öykülerdeki izleri ile tuvallerine taşımışlardır. 18. ve 19. yüzyıl ressamları, eserlerini farklı üslupların etkisiyle yaratmış olsalar da, Akdeniz'in doğal ve kültürel mirasına verdikleri değer konusunda hemfikir görünmektedirler. Tuvallerdeki Akdeniz, doğal ve tarihsel dokusuyla, güzel hisler kadar saygı da uyandırmaktadır. 


\section{KAYNAKÇA}

Antmen, A. (2008). Sanatçılardan Yazılar ve Açıklamalarla 20. Yüzyıl Batı Sanatında Akımlar. İstanbul: Sel Yayıncilik.

Benjamin, R. (1997). Orientalism: Delacroix to Klee. Sidney: The Art Gallery of New South Wales.

Braudel, F. (2008). Akdeniz: Tarih, Mekân, Insanlar ve Miras. İstanbul: Metis Yayınlar1.

Chilvers, I. (2009). Oxford Dictionary of Art \& Artists. Oxford: Oxford University Press.

Helstosky, C. (2009). Food Culture in the Mediterranean. Westport: Greenwood Press.

Higonnet, A. (1995). Berthe Morisot. California: University of California Press.

Maurer, N. E. (1999). The Pursuit of Spiritual Wisdom: The Thought and Art of Vincent van Gogh and Paul Gauguin. Cranbury: Assosicated University Presses.

Necatigil, B. (1969). 100 Soruda Mitologya. İstanbul: Gerçek Yayınevi.

Néret, G. (2004). Delacroix. Köln: Taschen.

Norman, G. (1977). Nineteenth Century Painters and Painting: A Dictionary. Berkeley: University of California Press.

Raeburn, M. (1985). Renoir. New York: Harry N. Abrams.

Tarabra, D. (2008). European Art of the Eighteenth Century. Los Angeles: Getty Publications.

Walter, E. (1984). Van Gogh in Arles. New York: The Metropolitan Museum of Art.

\section{Resim Listesi}

Fig. 1: Filippo Falciatore, Mergellina'da Tarantella, yak. 1750, tuval üzerine yağlıboya, 76,2 x 102, cm, Detroit Institute of Arts, Michigan.

Fig. 2: Claude-Joseph Vernet, Bir Akdeniz Limanı’nda Sükûnet, 1770, tuval üzerine yağlıboya, J. Paul Getty Museum, Los Angeles.

Fig. 3: Giovanni Battista Lusieri, Napoli Körfezi Manzarası: Pizzofalcone’den Capo di Posilippo’ya Güneybatı Bakışı, 1791, altı tane kâğıt üzerine suluboya, guaş ve mürekkep, J. Paul Getty Museum, Los Angeles.

Fig. 4: Johann Heinrich Wilhelm Tischbein, Goethe Roma'nın Kırlarında, 1787, Städelsches Kunstinstitut, Frankfurt.

Fig. 5: Jacob Philipp Hackert, Pompeii Kazıları, 1799, tuval üzerine yağlıboya, Attingham Park, Shropshire.

Fig. 6: James Barry, Jüpiter ve Juno İda Dă̆ı'nda, 1790-99, tuval üzerine yağlıboya, 130,2 cm x 155,4 cm, Sheffield City Museum, Sheffield.

Fig. 7: Eugène Delacroix, Akdeniz, 1837, sıva üzerine yağlıboya ve balmumu, 122 x $300 \mathrm{~cm}$, Salon du Roi, Palais Bourbon, Paris.

Fig. 8: Jules Joseph Lefebvre, Akdeniz Güzeli, pano üzerine yağlıboya, 34 x 51,5 cm, Özel Koleksiyon.

Fig. 9: Karl Blechen, Napoli Körfezi’nde Balıkçılar, 1830, tuval üzerine yağlıboya, 20 x 34 cm, Nationalgalerie, Berlin.

Fig. 10: Berthe Morisot, Nice'de Portakal Ağaçlı Villa, 1882, tuval üzerine yağlıboya, Özel Koleksiyon.

Fig. 11: Vincent van Gogh, Arles'te Kırmızı Bă̆, 1888, tuval üzerine yağlıboya, 75 x 93 cm, Pushkin Museum, Moskova.

Fig. 12: Vincent van Gogh, Sarı Güneş ve Gökyüzü ile Zeytin A ̆gaçları, 1889, tuval üzerine yağlıboya, 73,7 x 92,7 cm, Minneapolis Institute of Arts, Minnesota.

Fig. 13: Pierre Auguste Renoir, Arap Festivali, 1881, tuval üzerine yağlıboya, 73,5 x 92 cm, Musée D’Orsay, Paris. 
